Volume 10, Nomor 2, November 2018, pp 179-186 Copyright (C) 2017 Jurnal Akuntansi Maranatha, Program Studi Akuntansi, Fakultas Ekonomi,

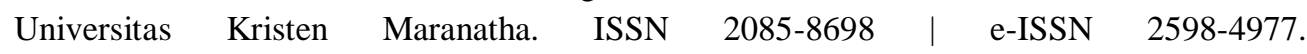
http://journal.maranatha.edu

\title{
Analisis Sistem Kompensasi Terhadap Kinerja Driver Transportasi Online
}

\author{
Fitriyah Nurhidayah \\ Program Studi Akuntansi - Universitas Pembangunan Jaya \\ fitriyah.nurhidayah@upj.ac.id
}

\begin{abstract}
Compensation and work performance are closely related. Adequate and proper compensation would generally drive employees to work better which later could boost up their work performance. This paper is aim to analyze the effect of compensation toward work performance at online transportation companies in Indonesia. The companies' policy on compensation as claimed by the emloyees have changed and made the employees uncomfortable. The research was conducted to 63 online transportation drivers. The primary data was used in this research. Questionnares were conducted to those online transportation drivers. This research used validity, reliability, regression analysis and t-test as part of research method. The result of the study showed that compesation effets the drivers' work performance by 53\%. The result of t-test, it has been proven that compensation significantly influence drivers' work performance.
\end{abstract}

Keywords: Compensation, Performance, Online Transportation, Online Transportation Drivers.

\section{Pendahuluan}

Saat ini kita telah berada pada era perkembangan teknologi dan informasi yang semakin maju, dimana teknologi telah menjadi bagian yang tidak bisa dipisahkan dalam kehidupan manusia. Berbagai kegiatan yang dilakukan juga saat ini dipermudah dengan hadirnya beragam aplikasi; mulai dari aplikasi untuk berbelanja, memasak, berbagi informasi, hingga aplikasi transportasi online. Aplikasi transportasi sendiri merupakan aplikasi yang cukup banyak digunakan oleh masyarakat Indonesia karena melalui aplikasi ini penggunanya dapat dengan mudah melakukan pembelian tiket, mengetahui jadwal pemberangkatan, hingga melakukan pemesanan jasa transportasi yang diperlukan. Salah satu aplikasi transportasi online yang populer di Indonesia saat ini adalah aplikasi penyedia platform yang menghubungkan driver (pengendara) berbagai jenis transportasi,mulai dari taksi dan layanan non taksi (motor dan mobil pribadi) dengan para penggunanya.

Perusahaan penyedia jasa transportasi berbasis aplikasi online, yang yang menghubungkan calon penumpang dan driver (pengendara) kendaraan melalui smartphone atau kadang disebut juga sebagai ride sharing business. Beberapa 
literatur menyebutkan perusahaan ini sebagai Ridesharing Economy Company yang berarti kondisi dimana asset yang tidak terpakai digunakan agar menjadi produktif (Wallsten, 2015). Perusahaanperusahaan ini selain memudahkan para pengguna jasa transportasi juga dapat meningkatkan geliat ekonomi masyarakat di daerah-daerah perkotaan (urban). Anggota masyarakat dapat meningkatkan personal income mereka dengan menjadi driver partner pada perusahaan transportasi berbasis online tersebut.

Terdapat beberapa faktor positif dan negatif yang bisa menjadi pertimbangan sebelum seseorang memutuskan untuk bergabung menjadi mitra/driver partner dari perusahaanperusahaan ini, antara lain:

1. Standar penghasilan yang cukup tinggi

2. Fleksibel, bekerja ketika diinginkan tanpa jadwal, tidak terikat.

3. Real-time tarif, mengetahui berapa banyak tarif penghasilan yang didapat dari setiap perjalanan. Baik pengemudi maupun penumpang akan langsung mengetahui berapa tariff untuk trip tersebut.

4. Pengendara, tidak membuang waktu/uang dalam menunggu penumpang.

5. Transparan, laporan pembayaran jelas dan transparan.

Namun di balik semua itu, kegiatan operasional yang dilakukan oleh perusahaan layanan transportasi online ini menimbulkan berbagai kontroversi baik dari pihak eksternal,maupun dari pihak internal. Di Indonesia sendiri kontroversi juga terjadi. Kesalahpahaman antara pengendara transportasi konvensional dan transportasi online terjadi di berbagai daerah.

Persaingan bisnis antar perusahaan penyedia jasa transportasi online $\mathrm{di}$ Indonesia juga semakin sengit. Perusahaanperusahaan ini berusaha untuk menghadirkan berbagai inovasi yang dapat menarik calon konsumen/pengguna untuk menggunakan jasa layanan transportasi mereka. Layanan yang disediakan juga kini tidak terbatas pada transportasi saja, namun sudah mengarah ke berbagai layanan lain, seperti jasa pembelian makanan dan jasa pengiriman barang. Selain itu, perusahaanperusahaan ini juga berlomba-lomba menghadirkan layanan dengan tarif termurah untuk menarik pengguna. Pemberian potongan tarif layanan hingga tarif promosi yang berkelanjutan diharapkan dapat meningkatkan jumlah konsumen/pengguna yang menggunakan layanan mereka.

Selama ini berbagai tarif promosi atau potongan harga yang diberikan perusahaan tidak mempengaruhi pendapatan para driver (pengendara), karena perusahaan akan membayarkan kekurangan tarif yang mendapatkan promosi atau potongan biaya. Selain itu mereka juga mendapatkan tambahan pendapatan dari bonus pengemudi. Namun sayangnya perusahaan seringkali merubah kebijakan terkait dengan bonus, sehingga mempengaruhi pendapatan yang diperoleh driver. Salah satu kebijakan baru yang ditetapkan terkait dengan bonus adalah penerapan sistem performa (performance) atau yang disebut juga dengan rating. Sistem performa diketahui merupakan sistem terbaru yang akan menentukan pendapatan bonus driver. Jika performa tidak terpenuhi, maka mereka terancam tidak akan mendapatkan bonus, di mana bonus tersebut menjadi tulang punggung mendongkrak pendapatan.

Perusahaan layanan transportasi online ada yang menetapkan system penghitungan performa yang ditetapkan dihitung berdasarkan rating harian masingmasing driver. Apabila rating harian mereka tidak mencapai 50\%, maka bonus akan hangus. Syarat yang harus dipenuhi untuk driver untuk menjaga rating atau performa mereka antara lain tidak adanya 
pembatalan (cancellation) dari pihak driver, tidak menolak order, dan selalu merespon order. Pembatalan yang dilakukan oleh pengguna/konsumen juga dapat berpengaruh terhadap performa driver (Pramono, 2016). Sementara perusahaan layanan transportasi lain menetapkan bonus berdasarkan performa driver yang selalu menerima order di jamjam sibuk. Semakin sering driver menerima order di jam sibuk, maka semakin besar bonus yang didapatkannya (Sugiharto, 2016).

Sayangnya kebijakan manajemen perusahaan terkait dengan sistem perfoma driver kerap kali berubah, dan perubahan ini selalu mengundang reaksi dari pihak driver. Kebijakan manajemen ini dikhawatirkan akan berpengaruh terhadap kinerja para driver. Apabila sistem penilaian performa ini kurang baik akan berpengaruh pada kinerja dan layanan yang diberikan driver kepada para penggunanya.

\section{Kerangka Teoritis dan Hipotesis}

\section{Transportasi Online}

Perusahaan transportasi berbasis aplikasi online atau sering disebut Transportation Network Companies (TNC) atau kadang disebut Ride Sharing Business adalah perusahaan yang menghubungkan calon penumpang dan pengendara kendaraan melalui smartphone. Calon penumpang dapat men-download aplikasi di smartphone mereka untuk memesan kendaraan yang mereka butuhkan. Pada aplikasi tersebut calon penumpang dapat melihat driver (pengendara) terdekat dari lokasi si calon penumpang.

Setelah calon penumpang melihat virtual map destinasi mereka beserta alokasi waktu yang dibutuhkan untuk tiba ke tempat tujuan, GPS akan dikirim ke driver yang akan mengambil order dari calon penumpang tersebut. Di aplikasi tersebut calon penumpang dapat memantau lokasi dari calon driver mereka dan estimasi waktu yang dibutuhkan calon driver untuk datang menjemput calon penumpang. Selain itu aplikasi tersebut dapat mengatur sistem pembayaran dan sistem review antara penumpang dan driver.

\section{Pengertian Kinerja}

Kinerja adalah hasil kerja secara kualitas dan kuantitas yang dicapai oleh seorang pegawai dalam melaksanakan tugasnya sesuai dengan tanggung jawab yang diberikan kepadanya. Kinerja adalah hasil kerja yang dapat dicapai oleh seseorang atau sekelompok orang dalam organisasi, sesuai dengan wewenang dan tanggung jawab masing-masing dalam rangka upaya mencapai tujuan organisasi secara legal, tidak melanggar hukum dan sesuai dengan moral maupun etika. Pengertian kinerja adalah hasil kerja secara kualitas dan kuantitas yang dicapai oleh seorang karyawan dalam melaksanakan tugasnya sesuai dengan tanggung jawab yang diberikannya.

\section{Kompensasi}

Kompensasi adalah imbalan, hadiah, atau ganjaran. Dalam konsep manajemen kompensasi adalah salah satu alat untuk meningkatkan motivasi para pegawai (Ivancevich, 2007: 226). Kompensasi merupakan sebagai bentuk apresiasi usaha untuk mendapatkan tenaga kerja yang profesional sesuai dengan tuntutan jabatan diperlukan suatu pembinaan yang berkeseimbangan, yaitu suatu usaha kegiatan perencanaan, pengorganisasian, penggunaan, dan pemeliharaan tenaga kerja agar mampu melaksanakan tugas dengan efektif dan efisien. Sebagai langkah nyata dalam hasil peembinaan maka diadakan pemberian kompensasi pegawai yang telah menunjukan prestasi kerja yang baik. Kompensasi adalah kan suatu pembinaan yang berkeseimbangan, yaitu suatu usaha kegiatan perencanaan, pengorganisasian, 
penggunaan, dan pemeliharaan tenaga kerja agar mampu melaksanakan tugas dengan efektif dan efisien. Sebagai langkah nyata dalam hasil peembinaan maka diadakan pemberian kompensasi pegawai yang telah menunjukan prestasi kerja yang baik.

\section{Metode Penelitian}

Penelitian ini dilakukan dengan metode penelitian deskriptif kuantitatif. Teknik pengambilan sampel didasarkan pada sample random sampling dengan mengambil sampel sebanyak 63 responden. Jenis dan sumber datanya adalah data primer. Pengumpulan data dilakukan melalui penyebaran questioner. Teknik analisa data penelitian dengan program SPSS 25.00 dengan alat analisis Uji Validitas, Uji Reliabilitas, Analisis Regresi dan Uji t.

Berdasarkan uraian diatas, kerangka pemikiran dalam penelitian ini disusun sebagai berikut :

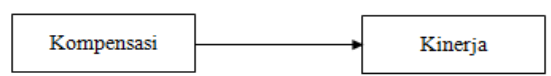

\section{Gambar 1 \\ Kerangka Pemikiran}

Variabel dalam penelitian disini meliputi :

a. Variabel independent yang digunakan dalam penelitian ini adalah kompensasi yang terdiri kompensasi finansial dan kompensasi non finansial. Adapun indikator pengukurannya adalah sebagai berikut

- Kompensasi finansial, indikatornya terdiri dari gaji, bonus dan program-program proteksi/perlindungan.

- Kompensasi non finansial, indikatornya terdiri dari pekerjaan dan lingkungan kerja

b. Variabel dependent yang digunakan dalam penelitian ini adalah kinerja. Adapun indikator pengukurannya adalah kriteria berdasarkan sifat, kriteria berdasarkan perilaku dan kriteria berdasarkan hasil.

\section{Hasil Penelitian dan Pembahasan}

Objek penelitian ini adalah driver (pengemudi) transportasi online di daerah Tangerang Selatan. Berikut merupakan gambaran profil responden dalam penelitian ini. Jenis kelamin responden pengemudi transportasi online dalam penelitian ini berjenis kelamin laki-laki 62 orang $(98 \%)$ dan berjenis kelamin perempuan 1 orang (2\%) dari responden. Usia responden 17-21 tahun sebanyak 2 orang (3\%), 22-26 tahun sebanyak 8 orang (13\%), 27-31 tahun sebanyak 22 orang $(35 \%)$, dan $32-36$ sebanyak 19 orang (30\%), 37-41 sebanyak 6 orang $(10 \%)$, 42-46 sebanyak 4 orang (6\%0 dan > 46 sebanyak 2 (3\%). Latar belakang pendidikan, responden yang memiliki pendidikan terakhir SD sebanyak 6 orang (10\%) SMP sebanyak 10 orang (16\%), SMA / SMK sebanyak 32 orang (51\%), Diploma 8 orang (13\%) dan Sarjana sebanyak 7 orang (11\%). Lamanya bekerja sebagai driver transportasi online yang bekerja < 1 tahun sebanyak 6 responden (10\%), sedangkan responden yang bekerja selama 1-2 tahun sebanyak 19 (30\%), 2-3 tahun sebanyak $28(44 \%)$ dan $>3$ tahun dan responden sebanyak 10 responden $(16 \%)$.

\section{Hasil Uji Validitas}

Uji validitas digunakan untuk mengetahui apakah alat ukur yang disusun dapat digunakan untuk mengukuir secara tepat. Validitas suatu instrument akan menggambarkan tingkat kemampuan alat ukur yang akan digunakan untuk mengungkapkan sesuatu yang menjadi sasaran pokok pengukuran. Suatu item dikatakan valid jika nilai $r$ hitung yang dihasilkan lebih besar dari nilai $r$ tabel. 


\section{Uji Reliabilitas}

Uji reliabilitas dimaksudkan untuk mengetahui adanya konsitensi alat ukur dalam penggunaannya. Suatu alat ukur dikatakan reliabel apabila dalam beberapa kali pelaksanaan pengukuran terhadap kelompok atau subjek yang sama diperoleh hasil yang relative sama, selama aspek dalam diri kelompok atau subjek yang diukur belum berubah. Untuk mencapai hal tersebut, dilakukan uji reliabilitas dengan menggunakan metode Alpha Cronbach's dengan nilai diatas 0,70 . Berikut adalah tabel hasil uji reliabilitas untuk penelitian ini :

\section{Tabel 1}

Nilai Cronbach's Alpha Kompensasi

\section{Reliability Statistics}

\begin{tabular}{|c|c|}
\hline Cronbach's Alpha & N of Items \\
\hline .929 & 23 \\
\hline
\end{tabular}

Sumber data : Data primer yang diolah

Tabel 2

Nilai Cronbach's Alpha Kinerja

\begin{tabular}{|c|c|}
\hline Cronbach's Alpha & N of Items \\
\hline .870 & 9 \\
\hline
\end{tabular}

Sumber data : Data primer yang diolah

Tabel 3

Uji Realibilitas Instrumen

\begin{tabular}{|l|l|l|l|l|}
\hline $\begin{array}{l}\mathbf{N} \\
\mathbf{o}\end{array}$ & Variabel & $\begin{array}{l}\text { Cronbach } \\
\text { 's Alpha }\end{array}$ & $\begin{array}{l}\text { Nilai } \\
\text { kriti } \\
\text { s }\end{array}$ & $\begin{array}{l}\text { Keteranga } \\
\mathbf{n}\end{array}$ \\
\hline 1 & $\begin{array}{l}\text { Kompensa } \\
\text { si }\end{array}$ & 0,929 & 0,70 & Reliable \\
\hline 2 & Kinerja & 0,870 & 0,70 & Reliable \\
\hline
\end{tabular}

Sumber : Data primer yang diolah 2018
Berdasarkan hasil pengujian alat ukur yang digunakan dalam penelitian ini, nilai alpha cronbach's yang dihasilkan berada diatas 0,70 maka alat instrument yang digunakan dalam penelitian ini dinyatakan reliable atau konsisten bila digubakan dalam beberapa kali pengukuran.

\section{Uji Normalitas Data}

Uji normalitas bertujuan untuk menguji apakah dalam model regresi varibel terikat dan variabel bebas keduanya mempunyai distribusi normal atau tidak. Model regresi yang baik adalah memiliki distribusi data normal atau mendekati normal. Pengujian normalitas dalam pengujian ini menggunakan analisis grafik. Dengan melihat probability plot, yang membandingkan distribusi sesungguhnya dengan distribusi normal. Distribusi normal akan membentuk sat ugaris lurus diagonal. Jika distribusi normal, maka garis yang menggambarkan data sesungguhnya akan mengikuti garis diagonalnya. Data yang berdistribusi normal jika data tersebut berbentuk sebuah lonceng yang kedua sisinya tidak terhingga atau data menyebar di sepanjang garis diagonal



\section{Gambar 2}

Hasil Uji Normalitas Menggunakan Grafik Histogram (Data Primer Diolah)

Berdasarkan gambar 2 terlihat distribusi data yang berbentuk lonceng dengan kedua sisi yang tidak terhingga, berdasarkan uji normalitas variabel dependent dan variabel independent memiliki distribusi normal. 


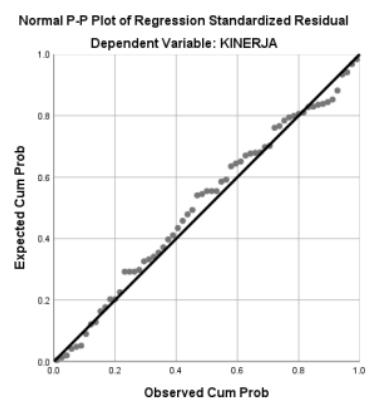

Gambar 3

\section{Grafik Normal P-P Plot of Regression}

Berdasarkan gambar 3 diatas terlihat bahwa data variabel dependent dan variabel independent mempunyai distribusi normal, karena data-data yang diolah banyak menyebar disekitar garis diagonal dan mengikuti garis diagonal tersebut, ini berarti data yang telah dilakukan pengujian memiliki distribusi normal dan dapat digunakan.

\section{Regresi Linier Sederhana}

Persamaan regresi sederhana digunakan untuk menggambarkan model hubungan antar variabel bebas dengan variabel terikatnya. Persamaan regresi ini memuat nilai konstanta atau intercept nilai koefisien regresi atau slope dan variabel bebasnya. Berdasarkan hasil penelitian, persamaan dalam analisis regresi linier sederhana dalam penelitian ini adalah :

$$
\begin{aligned}
& Y=a+b X+e \\
& Y=11,845+0,028+e
\end{aligned}
$$

Arti angka-angka dalam persamaan regresi diatas adalah :

a. Nilai konstanta (a) sebesar 11,845 artinya apabila kompensasi diasumsikan bernilai nol (0) maka tingkat kinerja tetap sebesar 0,028

b. Nilai koefisien regresi 0,239 menyatakan bahwa jika kompensasi mengalami peningkatan 1 satuan maka kinerja mengalami kenaikan sebesar 0,239

c. Standar error e merupakan variabel acak dan mempunyai pengaruh terhadap Y tetapi tiodak dimasukkan dalam persamaan.

\section{Hasil Uji t}

\section{Tabel 4}

Uji Realibilitas Instrumen

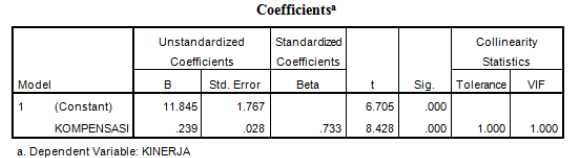

Berdasarkan tabel 4 diatas hasil penelitian mengenai pengaruh kompensasi terhadap kinerja menunjukkan nilai t hitung $(8,428)>\mathrm{t}$ tabel $(0,244)$ dengan nilai Signifikansi yang dihasilkan sebesar lebih kecil 0,000 berada dibawah $0.05(0.000<$ $0.05)$, sehingga dapat disimpulkan bahwa kompensasi berpengaruh positif dan signifikan terhadap kinerja driver transportasi online.

\section{Hasil Analisis Koefisien Determinasi}

Koefisien determinasi merupakan besarnya kontribusi variabel bebas terhadap variabel terikatnya.

\begin{tabular}{l|r|r|r|c|}
\hline Model & $\mathrm{R}$ & $\mathrm{R}$ Square & $\begin{array}{c}\text { Adjusted R } \\
\text { Square }\end{array}$ & $\begin{array}{c}\text { Std. Error of the } \\
\text { Estimate }\end{array}$ \\
\hline 1 & $.733^{\circ}$ & .538 & .530 & 2.50998 \\
\hline
\end{tabular}

b. Dependent Variable: KINERJA

Dari hasil tabel di atas, hasil Adjusted $R^{2}$ adalah 0.530. Hal ini berarti kompensasi mempengaruhi kinerja driver transportasi sebesar 53\% dan sisanya $47 \%$ dipengaruhi oleh faktor-faktor lain yang tidak diteliti dalam penelitian ini. 


\section{Simpulan dan Saran}

\section{Simpulan}

Hasil penelitian menunjukkan Adjusted R2 adalah 0,530 . Hal ini berarti kompensasi mempengaruhi kinerja driver transportasi sebesar $53 \%$ dan sisanya $47 \%$ dipengaruhi oleh faktor-faktor lain yang tidak diteliti dalam penelitian ini. Berdasarkan hasil uji t, diperoleh nilai Sig. lebih kecil daripada $0.05(0.000<0.05)$, sehingga dapat disimpulkan bahwa kompensasi berpengaruh positif dan signifikan terhadap kinerja driver transportasi online.

\section{Saran}

Berdasarkan hasil penelitian sebaiknya perusahaan tetap menerapkan sistem kompensasi yang baik kepada para driver transportasi online agar kinerja mereka dapat terus ditingkatkan sehingga dapat memberikan layanan yang terbaik kepada para penggunanya.

Kebijakan perusahaan yang seringkali berubah akan mempengaruhi pendapatan yang diperoleh driver. Salah satu kebijakan baru yang ditetapkan terkait dengan bonus adalah penerapan sistem performa (performance) atau yang disebut juga dengan rating. Sistem performa diketahui merupakan sistem terbaru yang akan menentukan pendapatan bonus driver. Jika performa tidak terpenuhi, maka mereka terancam tidak akan mendapatkan bonus, di mana bonus tersebut menjadi tulang punggung mendongkrak pendapatan. Apabila sistem penilaian performa ini kurang baik akan berpengaruh pada kinerja dan layanan yang diberikan driver kepada para penggunanya. Apabila sistem penilaian performa ini kurang baik akan berpengaruh pada kinerja dan layanan yang diberikan driver kepada para penggunanya.

\section{Daftar Pustaka}

Hall, J. V., \& Krueger, A. B. (2015). An Analysis of the Labor Market for Uber's Driver-Partners in the United States. Princeton University, Department of Economics and Woodrow Wilson School.

Handoko, T. Hani. 2003. "Manajemen Sumber Daya Manusia, Edisi 2". Yogyakarta: BPFE.

Isaac, E. (2014). Disruptive Innovation: Risk-Shifting and Precarity in the Age of Uber. University of California Davis.

Ivancevich, J. M. et al. (2007). Perilaku \& Manajemen Organisasi, Erlangga: Jakarta

Nawawi, Handari. 2005. "Manajemen Sumber Daya Manusia". Yogyakarta: Gadjah Mada.

Sugiharto, Bintoro Agung (2016) . "Membandingkan Sistem Penilaian Gojek, GrabBike, dan UberMotor", published on Oct 3, 2016 Retrieved on June 21, 2017 from

http://www.cnnindonesia.com/tekn ologi/20161004130258-185-

163176/ membandingkan-sistempenilaian-gojek-grabbike-danubermotor/

Pramono, Richo FX. (2016). "Curhat Driver Gojek soal Bonus Tak Cair GaraGara Sistem Rating", published on Oct 3, 2016. Retrieved on June 6, 2017 from http://news.liputan6.com/read/261 6462/curhat-driver-gojek-soalbonus-tak-cair-gara-gara-sistemrating

Pratama, Aditya Hadi. (2016). "Pengemudi GO-JEK Kembali Lancarkan Demo Terkait Sistem Performa, Ada Apa?", published on Oct 3, 2016. Retrieved on June 21, 2017 fromhttps://id.techinasia.com/siste 
Jurnal Akuntansi Maranathan Volume 10 Nomor 2, November 2018 : 179-186

m-performa-go-jek-untungkanpengguna-dikecam-pengemudi

Prawirosentono, Suyadi. 2008. "Manajemen

Sumber Daya Manusia Kebijakan

Kinerja Karyawan" Yogyakarta:

BPFE. 